\title{
Advanced malignant melanoma responds to Prunus mume Sieb. Et Zucc (Ume) extract: Case report and in vitro study
}

\author{
SHIGETO MATSUSHITA $^{1 *}$, KO-ICHI TADA ${ }^{1 *}$, KO-ICHI KAWAHARA ${ }^{2 *}$, KAZUHIRO KAWAI $^{1}$, \\ TERUTO HASHIGUCHI ${ }^{2}$, IKURO MARUYAMA ${ }^{2}$ and TAKURO KANEKURA ${ }^{1}$
}

\begin{abstract}
${ }^{1}$ Department of Dermatology, Field of Sensory Organology, and ${ }^{2}$ Department of Laboratory and Vascular Medicine, Cardiovascular and Respiratory Disorders Advanced Therapeutics, Graduate School of Medical and Dental Sciences, Kagoshima University, 8-35-1 Sakuragaoka, Kagoshima 890-8520, Japan
\end{abstract}

Received March 4, 2010; Accepted May 25, 2010

DOI: 10.3892/etm_00000089

\begin{abstract}
Malignant melanoma (MM) is an aggressive chemoresistant skin cancer characterized by rapid metastasis and a poor prognosis. Therefore, the development of innovative effective therapies is critical. MK615 is an extract from the Japanese apricot Prunus mume Sieb. Et Zucc (Ume). At a neutral pH, it contains natural chemical substances such as triterpenoids that exert anti-neoplastic effects in several types of cancers. We found that in patients with advanced MM, MK615 dramatically suppressed the cutaneous in-transit metastasis of the disease. Pre- and post-treatment comparison of tumors showed that the apoptotic index was significantly increased by MK615. In vitro studies, MTT assay, flow cytometric cell cycle analysis and immunofluorescence microscopy revealed that MK615 inhibited the growth of SK-MEL28 cells in a dose-dependent manner, increased the proportion of cells in sub-G1 phase and induced apoptosis. We further examined the expression of the receptor for advanced glycation end products (RAGE). RAGE is a multi-ligand receptor that binds to a novel cytokine, high mobility group box protein 1 (HMGB1), as well as advanced
\end{abstract}

Correspondence to: Professor Takuro Kanekura, Department of Dermatology, Field of Sensory Organology, Graduate School of Medical and Dental Sciences, Kagoshima University, 8-35-1 Sakuragaoka, Kagoshima 890-8520, Japan

E-mail: takurok@m2.kufm.kagoshima-u.ac.jp

*Contributed equally

Abbreviations: MM, malignant melanoma; RAGE, receptor for advanced glycation end products; HMGB1, high mobility group box protein 1; TdT, terminal deoxynucleotidyl transferase; TUNEL, TdT-mediated dUTP-biotin nick end-labeling; PBS, phosphate-buffered saline; DAB, diaminobenzidine; MTT, 3-(4,5-dimethylthiazol-2-yl)-2,5-diphenyltetrazolium bromide; PI, propidium iodide; FITC, fluorescein isothiocyanate; DAPI, 4',6diamidino-2-phenylindole; PET, positron emission tomography; PAGE, polyacrylamide gel electrophoresis; TBS, tris-buffered saline; HRP, horseradish peroxidase

Key words: Japanese apricot, Prunus mume Sieb. Et Zucc, triterpenoid, malignant melanoma glycation end products. There is evidence that RAGE/HMGB1 interactions enhance cell invasion in MM. Here, we present Western blotting and immunofluorescence microscopy data indicating that MK615 inhibited the expression of RAGE in SK-MEL28 cells, and suppressed the release of HMGB1 by SK-MEL28 cells. Our findings suggest that MK615 may be a valuable tool for treating MM and other malignant tumors.

\section{Introduction}

Malignant melanoma (MM) is a highly invasive fatal skin cancer arising from the abnormal proliferation of epidermal melanocytes (1). Its resistance to conventional cancer therapies including irradiation and chemotherapy (2) renders its treatment difficult.

MK615, an extract mixture of the Japanese apricot Prunus mume Sieb. Et Zucc, Ume, at a neutral pH, contains several triterpenoids (3), compounds derived from 30-carbon precursors (4). These compounds have been demonstrated to exert anti-neoplastic effects $(5,6)$. The extract of Ume has been reported to exert anticancer effects against gastric (3), breast (7), hepatocellular (8), colon (9) and pancreatic cancers (10). The mechanisms underlying these effects include the induction of apoptosis $(3,7)$ and autophagy (9) and the suppression of Aurora A kinase $(8,10)$ in cancer cells.

In the present study, after obtaining marked results by treating a patient with advanced MM with MK615, we investigated the mechanisms underlying the effect of MK615 using the human MM cell line SK-MEL28.

\section{Patients and methods}

Patients. The patient, a 67-year-old Japanese woman diagnosed with MM, provided prior written informed consent for use of her data in this report.

Chemicals. MK615 and Misatol ${ }^{\circledR}$ GL, containing an additive to render it drinkable, were provided by AdaBio Co. Ltd. (Takasaki, Japan).

TUNEL staining and evaluation of apoptosis in vivo. Apoptosis in skin cells from the patient was evaluated by 
the TdT-mediated dUTP-biotin nick end-labeling (TUNEL) method using the ApoTag ${ }^{\circledR}$ Plus Peroxidase in situ Apoptosis Detection kit (Chemicon, Temecula, CA) according to the manufacturer's instructions. Cell nuclei were stripped of proteins by incubation with $20 \mu \mathrm{g} / \mathrm{ml}$ Proteinase $\mathrm{K}$ (Invitrogen, Carlsbad, CA). The immune complexes were visualized by incubating skin sections with DAB-nickel (Vector, Burlingame, CA). They were then counterstained with methyl-green. The apoptotic index was estimated by determining the percentage of apoptotic cells under a light microscope at $x 400$ magnification. A minimum of 2,000 cells was counted in tumor sections. Positively stained tumor cells exhibiting the morphological characteristics of apoptosis were identified using standard criteria (11).

Cell lines. Human SK-MEL28 melanoma cells were maintained in DMEM medium containing 10\% fetal calf serum. The cells were confirmed to be mycoplasma-free.

Cell growth analysis. The growth of SK-MEL28 cells in the presence or absence of MK615 was determined by 3-(4,5-dimethylthiazol-2-yl)-2,5-diphenyltetrazolium bromide (MTT) colorimetric assay.

Cell cycle analysis. The cell cycle was analyzed by the propidium iodide (PI) method of Biswas et al (12). SK-MEL28 cells $\left(1 \times 10^{5} / \mathrm{ml}\right)$ were grown for $24 \mathrm{~h}$ in $60-\mathrm{mm}$ culture dishes containing 0,10 or $20 \mu \mathrm{l} / \mathrm{ml} \mathrm{MK615,} \mathrm{scraped} \mathrm{off,} \mathrm{and} \mathrm{centri-}$ fuged at 1,500 rpm for $10 \mathrm{~min}$. The cell pellets were fixed in $70 \%$ ethanol at $-20^{\circ} \mathrm{C}$ for $1 \mathrm{~h}$, incubated in $0.25 \mathrm{mg} / \mathrm{ml}$ ribonuclease A in PBS at room temperature, stained with PI (0.125 $\mathrm{mg} / \mathrm{ml}$ in PBS) for $30 \mathrm{~min}$, and subjected to flow cytometric analysis. Cells in the sub-G1 phase were considered to be apoptotic.

Determination of apoptosis in vitro by fluorescence microscopy. We determined apoptosis in vitro by immunofluorescence microscopy (13). Briefly, SK-MEL28 cells $\left(5 \times 10^{4} /\right.$ well $)$ in 4 -well culture dishes were treated with 0,10 or $20 \mu \mathrm{l} / \mathrm{ml}$ MK615 for 2, 4 and $8 \mathrm{~h}$ and incubated with Annexin V-fluorescein isothiocyanate (FITC) (Immunotech, France) according to the manufacturer's instructions. Cell nuclei were stained with 4',6-diamidino-2-phenylindole (DAPI; Dojindo, Kumamoto, Japan) and examined under an Axioskop microscope (Carl Zeiss, Oberkochen, Germany).

Western blotting. Cell lysate samples were subjected to $12 \%$ SDS-polyacrylamide gel electrophoresis (PAGE), and the separated proteins were then transferred to a nitrocellulose membrane (GE Healthcare Bio-sciences KK, Piscataway, NJ) as described previously (14). The membrane was blocked with 5\% non-fat dry milk in Tris-buffered saline (TBS; $\mathrm{pH}$ 7.4) containing $0.02 \%$ Tween-20 (TBST) for $1 \mathrm{~h}$ at room temperature and then incubated with the first antibody in TBST containing $1 \%$ non-fat dry milk (overnight at $4^{\circ} \mathrm{C}$ ). After washing, the membrane was incubated with horseradish peroxidase (HRP)-conjugated anti-rabbit IgG polyclonal antibody (Invitrogen) diluted 1:3000 in TBST containing 2.5\% non-fat dry milk ( $1 \mathrm{~h}$ at room temperature). The membrane was washed again, and the immunoreactive bands were visualized using the ECL detection system (GE Healthcare Bio-sciences KK).

Immunofluorescence microscopy. SK-MEL28 cells on culture slides were fixed in $4 \%$ paraformaldehyde and blocked with $1 \%$ bovine serum albumin (Sigma, St. Louis, MO) in PBS. After washing, the cells were incubated with RAGE antibody (Santa Cruz, CA) and washed. The slides were then incubated with Alexa-fluor 488 goat anti-rabbit IgG (Invitrogen) diluted 1:200, washed, and stained with DAPI. Cells were visualized under an Axioskop microscope.

Statistical analysis. Statistical analysis was carried out using the Student's t-test (15); $\mathrm{p}$-values $<0.05$ were regarded as significant.

\section{Results}

Improvement of clinical manifestations in the MK615-treated $M M$ patient. This 67-year-old Japanese woman presented with a black nodule and a freckle on her left sole. Based on clinical examinations a diagnosis of MM was made (Fig. 1a). We resected the primary cutaneous lesions and dissected the popliteal, inguinal and iliac lymph nodes. Multiple nodules appeared on her left thigh 15 months later (Fig. 1b). Histological examination of biopsy specimens disclosed intradermal tumor nests consisting of highly atypical cells positive for S100 protein, HMB45 and Melan-A (Fig. 1c). Positron emission tomography (PET) showed highly increased glucose uptake by multiple lesions on the left thigh (Fig. 1d). The lesions were diagnosed as cutaneous in-transit metastasis of $\mathrm{MM}$, and although we delivered $3 \times 10^{6}$ units of IFN- $\beta$ intravenously daily, the number of in-transit metastatic lesions gradually increased. After 4 months, we administered $13 \mathrm{~g}$ Misatol ${ }^{\circledR}$ GL perorally daily. After 5 months, the number of in-transit metastatic lesions was significantly decreased (Fig. 2a), and de-pigmentation was observed on some of the regressed tumors. On PET scans, the lesions on her left thigh were strikingly improved after MK615 administration (Fig. 2b). The apoptotic index determined by the TUNEL technique was clearly higher after MK615 treatment $(0.462 \pm 0.203$ vs. $0.165 \pm 0.039 \%$; $\mathrm{p}=0.00568$ ).

Inhibition of SK-MEL28 cell growth by MK615. The growth of SK-MEL28 cells in the presence or absence of MK615 was determined by MTT assay. The viability of MK615-treated SK-MEL28 cells was significantly decreased in a dose-dependent manner after a 24- and 48-h incubation (Fig. 3a).

Cell cycle retardation of SK-MEL28 cells by MK615. To examine the effects of MK615 on apoptosis we assessed the cell cycle of SK-MEL28 cells by flow cytometry using PI staining. In the presence of 10 and $20 \mu \mathrm{l} / \mathrm{ml}$ MK615, the proportion of sub-G1 cells was increased in a dose-dependent manner (Fig. 3b); $19.97 \pm 3.90$ and $23.07 \pm 2.73 \%$ at 10 and $20 \mu \mathrm{l} /$ $\mathrm{ml}$ MK615, respectively, and significantly higher than in cells cultured in the absence of MK615 ( $\mathrm{p}=0.00284$ and 0.00041 , Table I).

MK615-induced SK-MEL28 apoptosis. Fluorescence staining with Annexin V showed that at 10 and $20 \mu \mathrm{l} / \mathrm{ml}$, MK615 

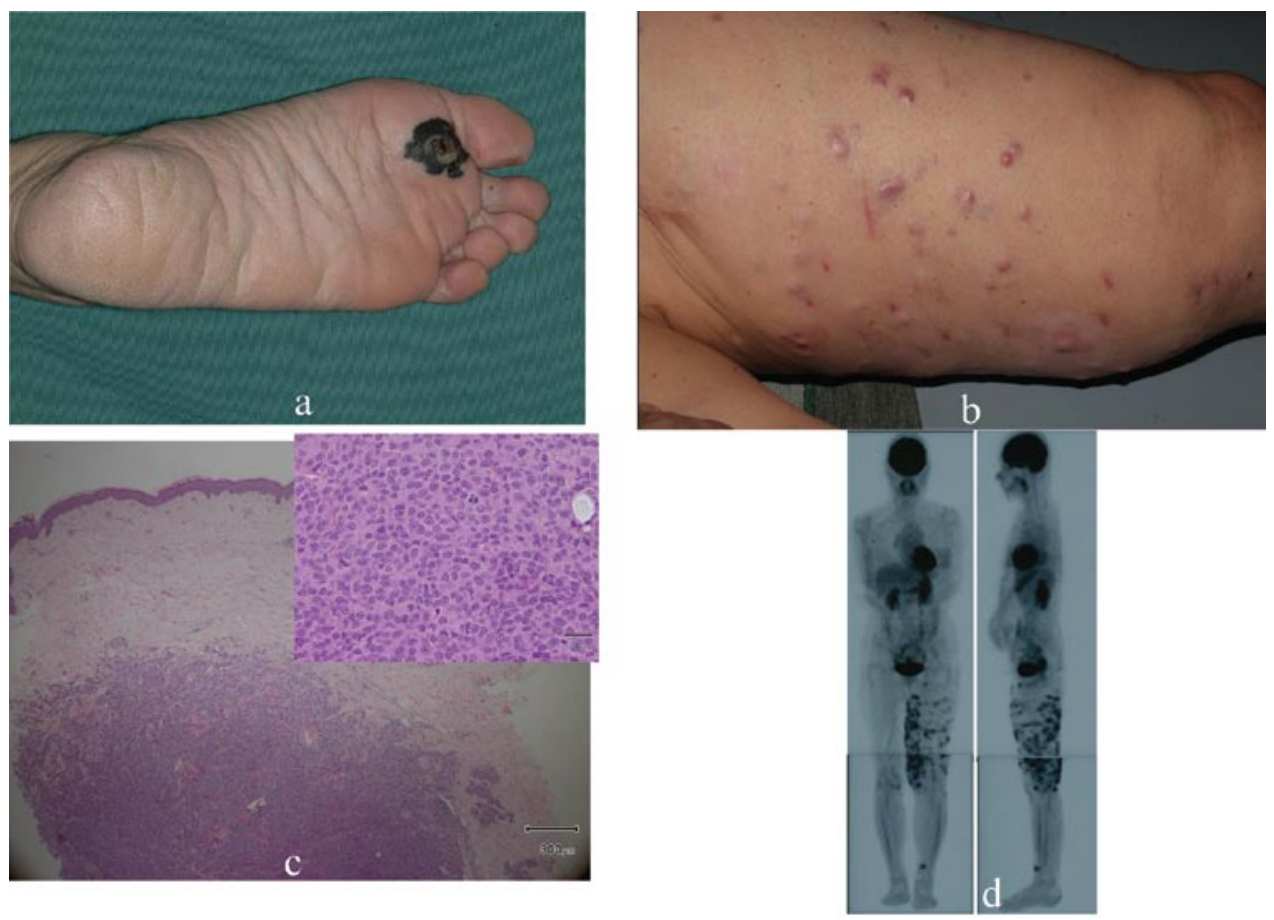

Figure 1. (a) A 67-year-old Japanese woman with MM on the sole of her left foot. (b) Multiple nodules on the left thigh indicating in-transit metastasis of MM. (c) Highly atypical cells and significant inflammatory infiltrates in the vicinity of the nodules in the dermis (hematoxylin and eosin; original magnification x40 and x100). (d) Positron emission tomography (PET) showed multiple glucose uptake on the left thigh.
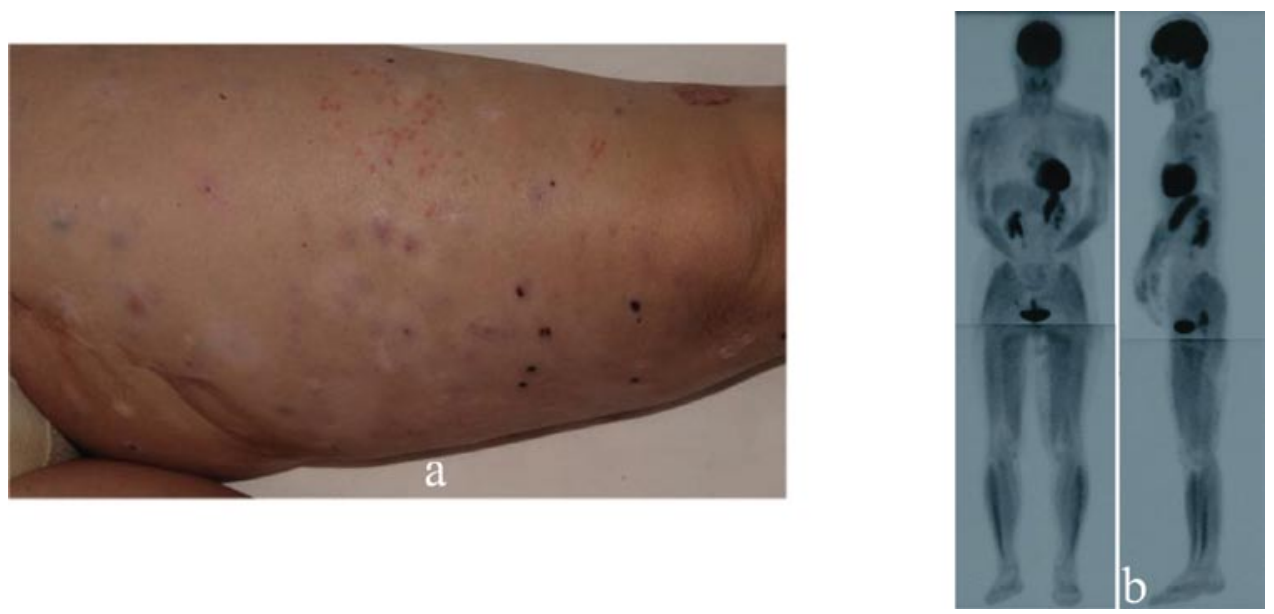

Figure 2. (a) Five months after the start of MK615 treatment, the number of in-transit metastases is clearly decreased. (b) PET showed improvement of the lesions on the left thigh after MK615 treatment.

Table I. The proportion of sub-G1 SK-MEL28 cells after exposure to the indicated doses of MK615.

\begin{tabular}{lr}
\hline MK615 $(\mu \mathrm{l} / \mathrm{ml})$ & sub-G1 $(\%)$ \\
\hline 0 & $1.80 \pm 0.50^{\mathrm{a}}$ \\
10 & $19.97 \pm 3.90^{\mathrm{b}}$ \\
20 & $23.07 \pm 2.73^{\mathrm{c}}$ \\
\hline
\end{tabular}

Each value represents the mean \pm SD of 3 independent experiments. Statistical significance was determined with the Student's t-test. a vs b, $\mathrm{P}=0.00284$; $\mathrm{a}$ vs $\mathrm{c}, \mathrm{P} 1=0.00041 ; \mathrm{b}$ vs c, $\mathrm{P}=0.409$. induced apoptosis as reflected by phosphatidylserine externalization. The number of apoptotic cells increased in a time-dependent manner (Fig. 3c).

Attenuation of RAGE expression in SK-MEL28 cells by MK615. Western blotting showed that MK615 inhibited RAGE expression by SK-MEL28 cells in a dose-dependent manner (Fig. 4a). Immunofluorescence analysis revealed that at $10 \mu \mathrm{l} / \mathrm{ml}$, MK615 abolished the expression of RAGE on the cell membrane (Fig. 4b).

MK615 inhibits HMGB1 release by SK-MEL28 cells. The concentration of HMGB1 in SK-MEL28 cell supernatants is 
$\mathbf{a}$

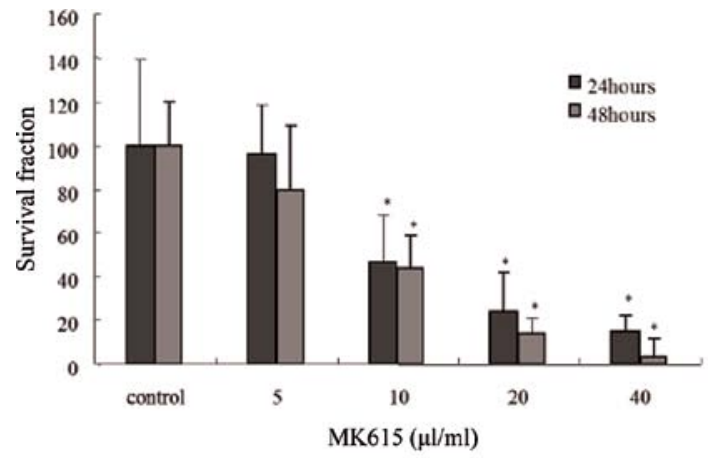

b

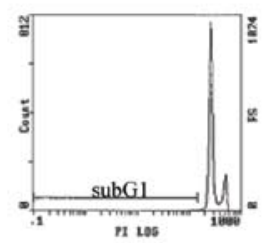

ctrl

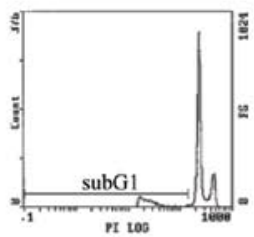

MK615 $10 \mu \mathrm{l} / \mathrm{ml}$

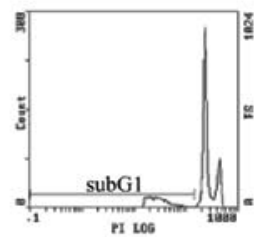

MK615 $20 \mu \mathrm{l} / \mathrm{ml}$

c
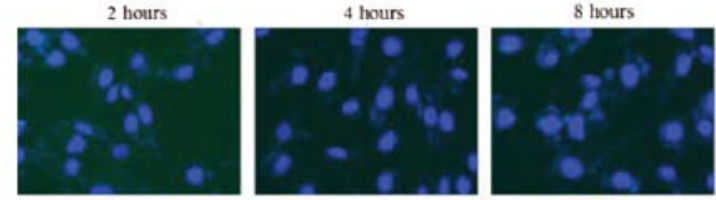

ctrl
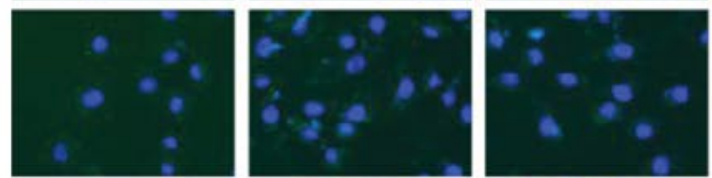

MK615

$10 \mu \mathrm{l} / \mathrm{ml}$
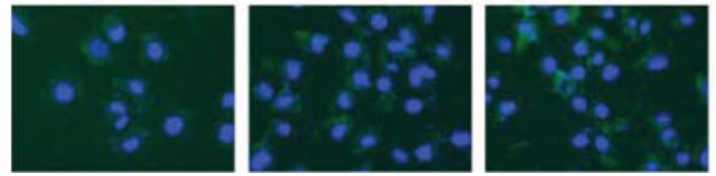

MK615

$20 \mu \mathrm{l} / \mathrm{ml}$

Figure 3. (a) The viability of SK-MEL28 cells treated with MK615 for 24 and $48 \mathrm{~h}$ was determined by MTT assay. Each time point represents the results of 6 experiments. The viability of SK-MEL28 cells treated with MK615 decreased significantly in a dose-dependent manner after a 24- and 48-h incubation. Statistical significance was determined by the Student's t-test. " $\mathrm{p}<0.05$ compared with MK615-untreated controls. (b) SK-MEL 28 cells were treated with 0,10 or $20 \mu \mathrm{l} / \mathrm{ml}$ MK615 for the indicated times. DNA components were analyzed by flow cytometry. MK615 treatment resulted in an increase in SK-MEL28 cells in the sub-G1 phase. (c) The effect of MK615 on phosphatidylserine externalization. Cells were treated with the indicated doses of MK615 for 2, 4 and $8 \mathrm{~h}$. Phosphatidylserine externalization was determined by Annexin V-FITC binding assay. Nuclei were stained blue by DAPI and green by Annexin V.

a

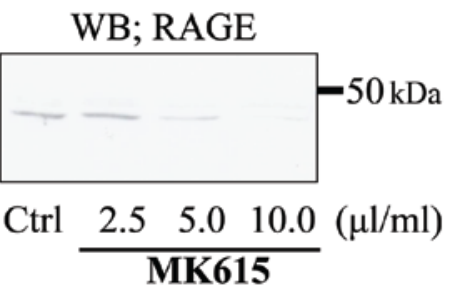

b

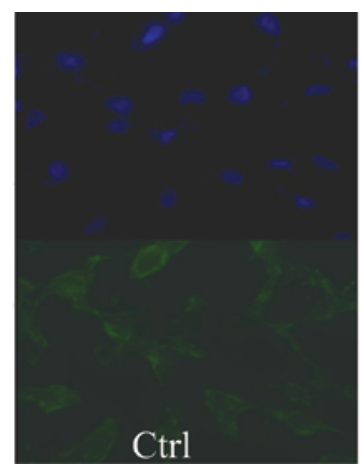

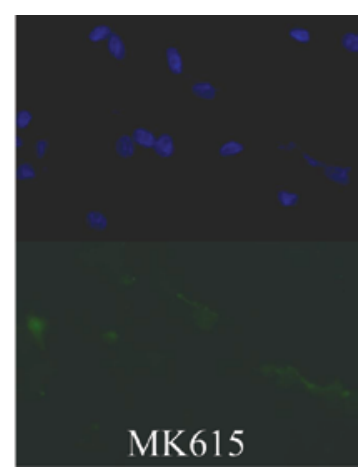

Figure 4. (a) RAGE expression in MK615-treated SK-MEL28 cells determined by Western blotting. SK-MEL28 cells were treated with $0,2.5,5$ and $10 \mu 1 /$ $\mathrm{ml}$ MK615 for $16 \mathrm{~h}$. RAGE expression of SK-MEL28 cells treated with MK615 decreased significantly in a dose-dependent manner. (b) SK-MEL28 cells were incubated with or without $5 \mu \mathrm{l} / \mathrm{ml}$ MK615 for $16 \mathrm{~h}$. Non-treated and MK615-treated cells were incubated with anti-RAGE antibody and then with FITClabeled anti-goat $\operatorname{IgG}$ as a secondary antibody. Nuclei were labeled with DAPI (original magnification, $\mathrm{x} 400$ ).

shown in Fig. 5. The SK-MEL28 cells spontaneously released $4.2 \pm 0.6 \mathrm{pg} / \mathrm{ml}$ HMGB1. MK615 significantly suppressed HMGB1 release in a dose-dependent manner.

\section{Discussion}

The Japanese apricot Ume has been accepted for centuries as a traditional medicine in Japan. It contains several chemical substances, e.g. citric and malic acid, cyanogenic glycosides and triterpenoids (3). Triterpenoids are natural or synthetic compounds derived from 30-carbon precursors (4). They have been shown to exert anti-neoplastic effects $(5,7)$. MK615 is a neutral $\mathrm{pH}$ extract mixture of the Ume fruit that contains several triterpenoids. It has been reported to exert anti-cancer effects against gastric (3), breast (7), hepatocellular (8), colon (9) and pancreatic cancer (10).

Here, we demonstrated that the Ume extract MK615 at a neutral $\mathrm{pH}$ suppressed cutaneous and in-transit metastatic lesions in a patient with MM. Pre- and post-treatment comparison showed that the apoptotic index of the tumor 


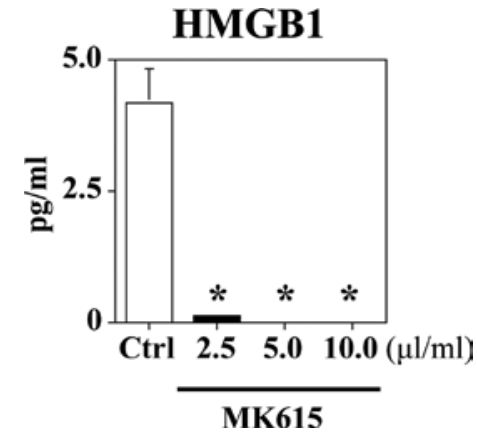

Figure 5. SK-MEL28 cells were incubated with $0,2.5,5$ and $10 \mu 1 / \mathrm{ml} \mathrm{MK615}$ for $16 \mathrm{~h}$. Supernatants were collected and analyzed by HMGB1 ELISA MK615 significantly suppressed HMGB1 release in a dose-dependent manner. Values are expressed as the mean $\pm \mathrm{SE}$ of triplicate experiments. ${ }^{*} \mathrm{P}<0.05$.

cells was significantly increased by MK615. We attributed the de-pigmentation of the regressed tumor portions to the activation of T-cell immunity against MM and melanocytes (16). Triterpenoids have been reported to regulate the cell cycle. Sun et al (17) showed that, in HeLa cells, triterpenoids induced apoptosis by cell cycle deviation resulting in S-phase accumulation and a decrease in G0-G1 phase cells. Other researchers (6) have documented triterpenoid-induced G2-M phase arrest, suggesting that cell cycle deviation plays a key role in the induction of apoptosis. Gutterman et al (5) demonstrated that, in pancreatic cancer cell lines, Ume extract increased the proportion of cells in the G2-M phase and inhibited Aurora A and B kinases. Aurora kinases are key mediators of cell deviation by controlling chromatoid segregation (18-20). In our study, the exposure of SK-MEL28 melanoma cells to MK615 resulted in an increase in cells in the sub-G1 phase. Moreover, we detected Annexin V-positive apoptotic cells $2 \mathrm{~h}$ after the start of MK615 exposure, and their number continued to increase up to $8 \mathrm{~h}$. These data suggest that MK615 induces apoptosis in MM cells by another pathway.

RAGE, a multi-ligand receptor, is highly expressed and is associated with cell invasion and migration (21). In a primary tumor model, anti-RAGE and soluble RAGE partially inhibited local tumor growth (21). Therefore, RAGE blockade may contribute to reducing tumor growth and invasion.

HMGB1, the ligand of RAGE, has two distinct functions in cellular systems. In the nucleus, HMGB1 acts as an intracellular regulator of the transcription process and plays a crucial role in the maintenance of DNA functions (22). In the extracellular space, HMGB1 is released by all eukaryotic cells upon necrosis or by macrophages in response to inflammatory stimuli such as endotoxin. Extracellular HMGB1 plays a major role in several diseases such as sepsis (22), rheumatoid arthritis, disseminated intravascular coagulation, periodontitis, xenotransplantation and atherosclerosis $(13,22-25)$.

Extracellular matrix associated HMGB1 promotes neurite outgrowth and provides a surface for the assembly of protease complexes in the fibrinolytic system, which can contribute to cell mobility. In view of the increased expression of HMGB1 and RAGE in tumors, the tumor bed may be an ideal locus for the effects of RAGE/HMGB1 interactions on cell migration and invasion.
Our study demonstrated that MK615 decreased the expression of RAGE in SK-MEL28 cells. Moreover, it significantly suppressed the release of HMGB1 by SK-MEL28 cells. Our results suggest that MK615 inhibits cell migration and invasion.

In summary, MK615 was effective in a patient with advanced MM. Our in vitro studies showed that it inhibited the growth of MM cells and increased the proportion of apoptotic cancer cells. MK615 may be a valuable tool for treating MM and other malignant tumors and further studies to evaluate its clinical effectiveness and to elucidate the precise mechanisms of its actions are warranted.

\section{Acknowledgements}

We thank Nobue Uto, Tomoka Nagasato and Tomomi Morizono for their excellent technical assistance. This study was supported by research grants from the Ministry of Education, Culture, Sports, Science, and Technology of Japan, by Grantsin-Aid 21390483 (to K.K.).

\section{References}

1. Houghton AN and Polsky D: Focus on melanoma. Cancer Cell 2: $275-278,2002$.

2. Soengas MS and Lowe SW: Apoptosis and melanoma chemoresistance. Oncogene 22: 3138-3151, 2003.

3. Adachi M, Suzuki Y, Mizuta T, Osawa T, Suzuki K, Shiojima K, Arai Y, Masuda K, Uchiyama M and Oyamada T: The Japanese apricot 'Prunus mume Sieb. Et Zucc' (Ume) is a rich natural source of novel anti-cancer substance. Int J Food Prop 10: 375-384, 2007.

4. Xu R, Frazio GC and Matsuda PT: On the origins of triterpenoid skeletal diversity. Phytochemistry 65: 261-291, 2004.

5. Gutterman JU, La HT, Yang P, Haridas V, Gaikwad A and Marcus S: Effects of the tumor inhibitory triterpenoid avicin G on cell integrity, cytokinesis, and protein ubiquitination in fission yeast. Proc Natl Acad Sci USA 102: 12771-12776, 2005.

6. Ramachandran C, Rabi T, Fonseca HB, Melnick SJ and Escalon EA: Novel plant triterpenoid drug amooranin overcomes multidrug resistance in human leukemia and colon carcinoma cell lines. Int J Cancer 105: 784-789, 2003.

7. Nakagawa A, Sawada T, Okada T, Ohsawa T, Adachi M and Kubota K: New antineoplastic agent, MK615, from Ume (a variety of) Japanese apricot inhibits growth of breast cancer cells in vitro. Breast J 13: 44-49, 2007.

8. Okada T, Sawada T, Osawa T, Adachi M and Kubota K: A novel anti-cancer substance, MK615, from ume, a variety of Japanese apricot, inhibits growth of hepatocellular carcinoma cells by suppressing Aurora A kinase activity. Hepatogastroenterology 54: 1770-1774, 2007.

9. Mori S, Sawada T, Okada T, Ohsawa T, Adachi M and Keiichi K: New anti-proliferative agent, MK615, from Japanese apricot 'Prunus mume' induces striking autophagy in colon cancer cells in vitro. World J Gastroenterol 13: 6512-6517, 2007.

10. Okada T, Sawada T, Osawa T, Adachi M and Kubota K: MK615 inhibits pancreatic cancer cell growth by dual inhibition of Aurora A and B kinases. World J Gastroenterol 14: 1378-1382, 2008.

11. Ansari B, Coates PJ, Greenstein BD and Hall PA: In situ endlabeling detects DNA strand breaks in apoptosis and other physiological and pathological states. J Pathol 170: 1-8, 1993.

12. Biswas KK, Sarker KP, Abeyama K, Kawahara K, Iino S, Otsubo Y, Saigo K, Izumi H, Hashiguchi T, Yamakuchi M, Yamaji K, Endo R, Suzuki K, Imaizumi H and Haruyama I: Membrane cholesterol but not putative receptors mediates anandamide-induced hepatocyte apoptosis. Hepatology 38: 1167-1177, 2003.

13. Kawahara K, Setoyama K, Kikuchi K, Biswas KK, Kamimura R, Iwata M, Ito T, Morimoto $\mathrm{Y}$, Hashiguchi $\mathrm{T}$, Takao $\mathrm{S}$ and Maruyama I: HMGB1 release in co-cultures of porcine endothelial and human T cells. Xenotransplantation 14: 636-641, 2007. 
14. Morimoto Y, Kawahara KI, Tancharoen S, Kikuchi K, Matuyama T, Hashiguchi T, Izumi Y and Maruyama I: Tumor necrosis factor-alpha stimulates gingival epithelial cells to release high mobility-group box 1. J Periodontal Res 43: 76-83, 2008.

15. Zar JH: Biostatistical Analysis. 3rd edition. Prentice Hall, New Jersey, 1996.

16. Lengagne R, Le Gal FA, Garcette M, Fiette L, Ave P, Kato M, Briand JP, Massot C, Nakashima I, Rĕnia L, Guillet JG and Prĕvost-Blondel A: Spontaneous vitiligo in an animal model for human melanoma: Role of tumor-specific $\mathrm{CD}^{+} \mathrm{T}$ cells. Cancer Res 64: 1496-1501, 2004.

17. Sun HX, Zheng QF and Tu J: Induction of apoptosis in HeLa cells by 3beta-hydroxy-12-oleanen-27-oic acid from the rhizomes of Astilbe chinensis. Bioorg Med Chem 14: 1189-1198, 2006.

18. Fu J, Bian M, Jiang Q and Zhang C: Roles of Aurora kinases in mitosis and tumorigenesis. Mol Cancer Res 5: 1-10, 2007.

19. Naruganahalli KS, Lakshmanan M, Dastidar SG and Ray A: Therapeutic potential of Aurora kinase inhibitors in cancer. Curr Opin Investig Drugs 7: 1044-1051, 2006.

20. Brittle AL and Ohkura H: Centrosome maturation: Aurora lights the way to the poles. Curr Biol 15: 880-882, 2005.

21. Taguchi A, Blood DC, del Toro G, Canet A, Lee DC, Qu W, Tanji N, Lu Y, Lalla E, Fu C, Hofmann MA, Kisilinger T, Ingram M, Lu A, Tanaka H, Hori O, Ogawa S, Stern DM and Schmidt AM: Blockade of RAGE-amphoterin signaling suppresses tumor growth and metastases. Nature 18: 354-360, 2000.
22. Wang $\mathrm{H}$, Bloom $\mathrm{O}$, Zhang $\mathrm{M}$, Vishnubhakat JM, Ombrellio M, Che J, Frazier A, Yang H, Ivanova S, Borovikova L, Manogue KR, Faist E, Abraham E, Andersson J, Andersson U, Molina PE, Abumrad NN, Sama A and Tracey KJ: HMG-1 as a late mediator of endotoxin lethality in mice. Science 285:m248-251, 1999

23. Taniguchi N, Kawahara K, Yone K, Hashiguchi T, Yamakuchi M, Goto M, Inoue K, Yamada S, Ijiri K, Matunaga S, Nakajima T, Komiya S and Maruyama I: High mobility group box chromosomal protein 1, a DNA binding cytokine, induces arthritis. Arthritis Rheum 48: 971-981, 2003.

24. Ito $T$, Kawahara $K$, Okamoto $K$, Yamada $S$, Yasuda $M$, Imaizumi H, Nawa Y, Meng X, Shrestha B, Hashiguchi T, Maruyama I: Proteolytic cleavage of high mobility group box 1 protein by thrombomodulin complexes. Arterioscler Thromb Vasc Biol 28: 1825-1830, 2008.

25. Inoue K, Kawahara K, Biswas KK, Ando K, Mitsudo K, Nobuyoshi M and Maruyama I: HMGB1 expression by activated vascular smooth muscle cells in advanced human atherosclerosis. Cardiovasc Pathol 16: 136-143, 2007. 